\title{
INHALT
}

Vorwort von Ulrich PFEIL

I. Beharrung und Wandlung in der

deutschen Geschichtswissenschaft nach 1945

Christoph CORNELISSEN

Deutsche Geschichtswissenschaft nach 1945. Zwischen nationalen

Traditionen und transnationalen Öffnungen

Thomas ETZEMÜLLER

Auf der Suche nach den »haltenden Mächten«. Intellektuelle Wandlungen und Kontinuitäten in der westdeutschen Geschichtswissenschaft nach 1945

\section{Axel SCHILDT}

Zur Hochkonjunktur des »christlichen Abendlandes« in der westdeutschen Geschichtsschreibung

II. Reinstitutionalisierung und Neuorientierung der bundesdeutschen Geschichtswissenschaft nach 1945

Anne Chr. NAGEL

„Gipfeltreffen der Mediävisten«. Der Konstanzer Arbeitskreis für mittelalterliche Geschichte

Michael Matheus

Die Wiedereröffnung des Deutschen Historischen Instituts 1953 in Rom. Transalpine Akteure zwischen Unione und Nation

Rainer RIEMENSCHNEIDER

Georg Eckert und das Internationale Schulbuchinstitut in Braunschweig

Astrid M. ECKERT

Notwendige Kooperation. Westdeutsche Zeitgeschichte als transnationales

Projekt in den 1950er Jahren

III. Deutsch-französische Historikerbeziehungen nach 1945

\section{Peter SCHÖTTLER}

Die deutsche Geschichtswissenschaft und Marc Bloch. Die ersten Nachkriegsjahrzehnte 
Agnès GraCEFFA

Deutsche Geschichtsschreibung aus der Sicht französischer Historiker.

Das Beispiel des Frühmittelalters

\section{Corine DEFRANCE}

Die internationalen Historikertreffen von Speyer. Erste Kontaktaufnahme zwischen deutschen und französischen Historikern nach dem Zweiten

Weltkrieg

Winfried SCHULZE

Zwischen Abendland und Westeuropa. Die Gründung des Instituts für Europäische Geschichte in Mainz im Jahre 1950

Heinz DUCHHARDT

Martin Göhring und seine Beziehungen zur französischen

Geschichtswissenschaft

IV. »Zerfall der historischen Ökumene« in Deutschland

\section{Mario KESSLER}

Geschichtswissenschaft nach 1945. Personelle Beharrung, Brüche und Neuanfang in beiden deutschen Staaten

Martin SABROW

Die deutsch-deutschen Historikerbeziehungen zwischen Abschließung und Öffnung

Ulrich PFEIL

Deutsche Historiker auf den internationalen Historikertagen von

Stockholm (1960) und Wien (1965). Geschichtswissenschaft zwischen

Internationalität und Freund-Feind-Denken im Kalten Krieg

Ernst SCHULIN

Zusammenfassung und Ausblick

Personenregister

Autorinnen und Autoren 